\title{
High-Intensity Focused Ultrasound (HIFU)-Assisted Hepatic Resection in an Animal Model
}

\author{
Alessandro Gandini, $\mathrm{MD}^{1}$, David Melodelima, $\mathrm{PhD}^{2}$, Francesco Schenone, $\mathrm{MD}^{\mathbf{1}}$, Apoutou William N'Djin, $\mathrm{PhD}^{2}$, \\ Jean Yves Chapelon, $\mathbf{P h D}^{2}$, and Michel Rivoire, $\mathrm{MD}, \mathbf{P h D}^{1}$ \\ ${ }^{1}$ Institut de chirurgie expérimentale, CRLCC Léon Bérard, Lyon, France; ${ }^{2}$ Applications des ultrasons à la thérapie \\ INSERM, Université Claude Bernard-Lyon I, Lyon, France
}

\begin{abstract}
Background. Bleeding is the main cause of postoperative complications of hepatic surgery. To minimize intraoperative bleeding during hepatectomy, resections are generally carried out under hepatic vascular control despite the risk of liver dysfunction in patients with chronic liver disease. This study evaluates the feasibility and safety of highintensity focused ultrasound (HIFU)-assisted hepatic resection during an open procedure in an animal model.

Methods. Three groups of 12-14-week-old Landrace pigs ( $n=7$ /group) were used to evaluate HIFU-assisted liver resection (group A) vs liver resection with or without portal triad clamping (groups B and C). In each pig, liver resection was performed on the right and left paramedian lobes. The following were evaluated and compared in the 3 groups: total blood loss, blood loss $/ \mathrm{cm}^{2}$ of resection area, clip density, procedure duration, morbidity, and mortality. Results. Median blood loss was significantly lower in group A than in group B $(P=.02)$, and group $\mathrm{C}$ $(P=.007)$. Median blood loss $/ \mathrm{cm}^{2}$ of resection area was $4.77 \mathrm{~mL} / \mathrm{cm}^{2}$ in group A, $11.35 \mathrm{~mL} / \mathrm{cm}^{2}$ in group $\mathrm{B}$, $12.22 \mathrm{~mL} / \mathrm{cm}^{2}$ in Group C. Precoagulation resulted in sealing blood vessels $<5 \mathrm{~mm}$; therefore, median clip density during liver transection was $0.78 \mathrm{clip} / \mathrm{cm}^{2}$ in group A, $1.61 \mathrm{clip} / \mathrm{cm}^{2}$ in group B, and $1.57 \mathrm{clip} / \mathrm{cm}^{2}$ in group C.
\end{abstract}

(C) The Author(s) 2011. This article is published with open access at Springerlink.com

First Received: 23 December 2010;

Published Online: 28 July 2011

A. Gandini, MD

e-mail: alessandro_gandini@fastwebnet.it
Median duration of the surgical procedure was $12 \mathrm{~min}$ in group A, $21 \mathrm{~min}$ in group B, and $19 \mathrm{~min}$ in group C.

Conclusions. HIFU-assisted hepatic resection during an open procedure in an animal model is safe, reduces bleeding, and allows real-time ultrasound guidance.

Bleeding is the main cause of postoperative complications of hepatic surgery. When a perioperative transfusion is needed, morbidity, mortality, and tumor recurrence increase. Thus, control of blood loss is imperative for reducing hematic transfusions during hepatic resection. ${ }^{1-4}$

As the hepatic parenchyma tolerates ischemia better than bleeding, intraoperative maneuvers have been proposed to minimize the risk of intraoperative bleeding during hepatic resection (e.g., total vascular exclusion, the Pringle maneuver, and selective ligature to control hepatic inflow).$^{5-8}$ None of these methods is completely effective, and each carries a risk of inducing liver dysfunction in patients with chronic liver disease. Vascular clamping is a time-critical technique, since higher morbidity results if it lasts more than 45 min. ${ }^{9,10}$

Hepatic resection techniques have been improved using devices such as bipolar forceps, water jet dissectors, ultrasonic cutting systems, argon coagulation, and others. ${ }^{11}$ These techniques are both expensive and time consuming. Recently, new approaches have been developed for performing bloodless hepatic resection without any vascular exclusion using energy sources such as radiofrequency, ultrasonic scalpels, and microwave coagulation. ${ }^{12-15}$ Among these alternative techniques, the use of highintensity focused ultrasound (HIFU) holds great promise because of its potential advantages, which include echographic targeting and no need to puncture. The feasibility of HIFU for the ablation of liver tumors have been demonstrated previously, and we describe in a previous study how HIFU induces homogeneous lesions. ${ }^{16-19}$ 
The aim of this study was to evaluate the feasibility of HIFU for hepatic resection in an animal model, with a focus on evaluation of blood loss and safety.

\section{MATERIALS AND METHODS}

All experiments were conducted at the Experimental Surgery Institute of the Centre Léon Bérard (Lyon, France) after approval of the local institutional review board. These experiments were in accordance with the requirements of the local Ethical Committee and with the legal conditions of the National Commission on Animal Experimentation.

\section{Animal Model}

This study used 12-14-week old Landrace pigs. Pigs are the most frequently used animals for experimental hepatic resection because the size and physiology of the porcine liver are similar to human liver. Preliminary surgical procedures were performed on 4 pigs to optimize the HIFUassisted resection technique, to investigate tolerance to hepatic resection, and to verify that the blood loss was less than $10 \mathrm{~mL} / \mathrm{kg}$ using standardized surgical techniques.

\section{HIFU Equipment}

The HIFU source used in this study had a toroid transducer with an integrated ultrasound imaging probe. ${ }^{19}$ Compared with conventional HIFU treatment, the ultrasound fields were generated by 8 ultrasound emitters operating at a frequency of $3 \mathrm{MHz}$. With this technology, the destruction zone induced in $40 \mathrm{~s}$ has a diameter of $2 \mathrm{~cm}$, a major axis of $3 \mathrm{~cm}$, and is placed at $7 \mathrm{~cm}$ from the emitting surface to enable treatment of the deepest region of the liver. ${ }^{20}$ The HIFU probe was brought into contact with the liver using a sterile ultrasound cooling and coupling liquid (Ablasonic, Edap-Technomed, Vaulx en Velin, France) in a sterile polyurethane envelope (Civco, Kalona, IA) (Fig. 1). Because of the thickness of the porcine liver (2-4 cm), the coupling sterile envelope was filled such that approximately $50-60 \mathrm{~mm}$ of liquid was present between the device and liver to correctly place the focus. Nevertheless, it is possible to change the location of the focal zone by adjusting the quantity of coupling liquid present between the device and tissues or by electronic focusing. Under these conditions, the location of the focal zone can be placed from the surface of the liver to $9 \mathrm{~cm}$ in depth. Such parameters permit treatment of the entire plane of resection. A 7.5-MHz ultrasound imaging probe was placed in the center of the device and connected to a BK HAWK 2102 EXL scanner (B-K Medical, Herlev, Denmark) to
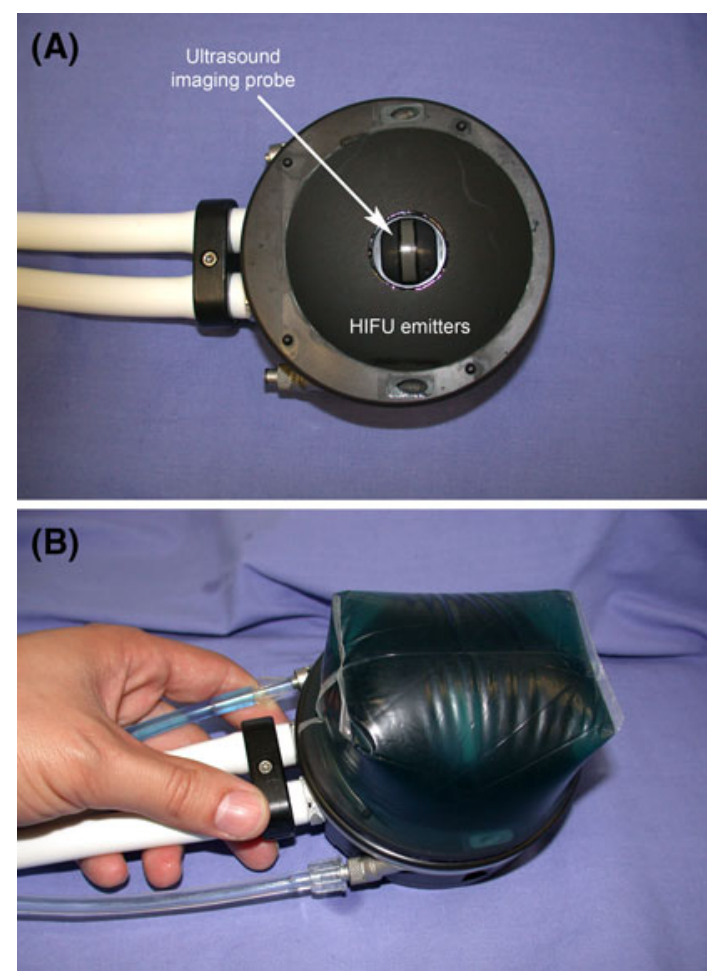

FIG. 1 a Front view of the HIFU therapy hepatic imaging probe. b High-intensity focused ultrasound (HIFU) therapy hepatic imaging probe

guide the resection procedure (Fig. 1) and allows sonogram visualization of the region that will be coagulated by ultrasound exposure: the position of the HIFU focal region is superimposed on the ultrasound image. ${ }^{21,22}$ In this way, the surgeon could precisely visualize the treatment zone within the hepatic tissue.

In this study, the HIFU toroid transducer was manually applied to the surface of the liver by the surgeon.

\section{Animal Care and Surgical Procedures}

The pigs were housed on-site 7 days before surgery and fasted for $24 \mathrm{~h}$ prior to surgery. ${ }^{23}$ Plasma samples were withdrawn from each animal from a central venous catheter prior to surgery for the following laboratory determinations: hemoglobin level, hematocrit, thrombocyte count, aspartate aminotransferase, alanine aminotransferase, prothrombin time, activated partial thromboplastin time, bilirubin, and ammonia.

HIFU-assisted resection (group A) was compared with standard surgical liver resection with or without vascular clamping (group B, positive control, and group C, negative control, respectively). Premedication, induction, and anesthesia were performed as reported previously by N'Djin et al.. ${ }^{19}$ In all animals, a $25-\mathrm{cm}$ median laparotomy was performed under sterile conditions. The liver was 
mobilized and exposed by surgical mops. The resection line was marked using a sterile marker. Liver echography was carried out by a $12-\mathrm{MHz}$ linear probe on the parenchyma to be resected, and all the main vessels within the resection line (hepatic veins and portal veins) were marked on the glissonian surface for tracing during resection. A cholecystectomy was performed routinely to eliminate the possibility of affecting the gallbladder during resection.

The surgical procedure was: systematic control of the major blood vessels was first established, then 2 hepatic resections (right and left paramedian lobes, segments IV, $\mathrm{V}$, and VIII) were performed in each animal. The resection line was located at the level of the division between the left and right median lobes (Fig. 2).

In group A, resection was performed after precoagulation of the hepatic parenchyma by HIFU. This allowed bloodless resection without using hepatic stalk clamping. Precoagulation was intended to establish a defined full thickness plane of coagulative necrosis; this was achieved by multiple side-to-side 40 -second HIFU treatments
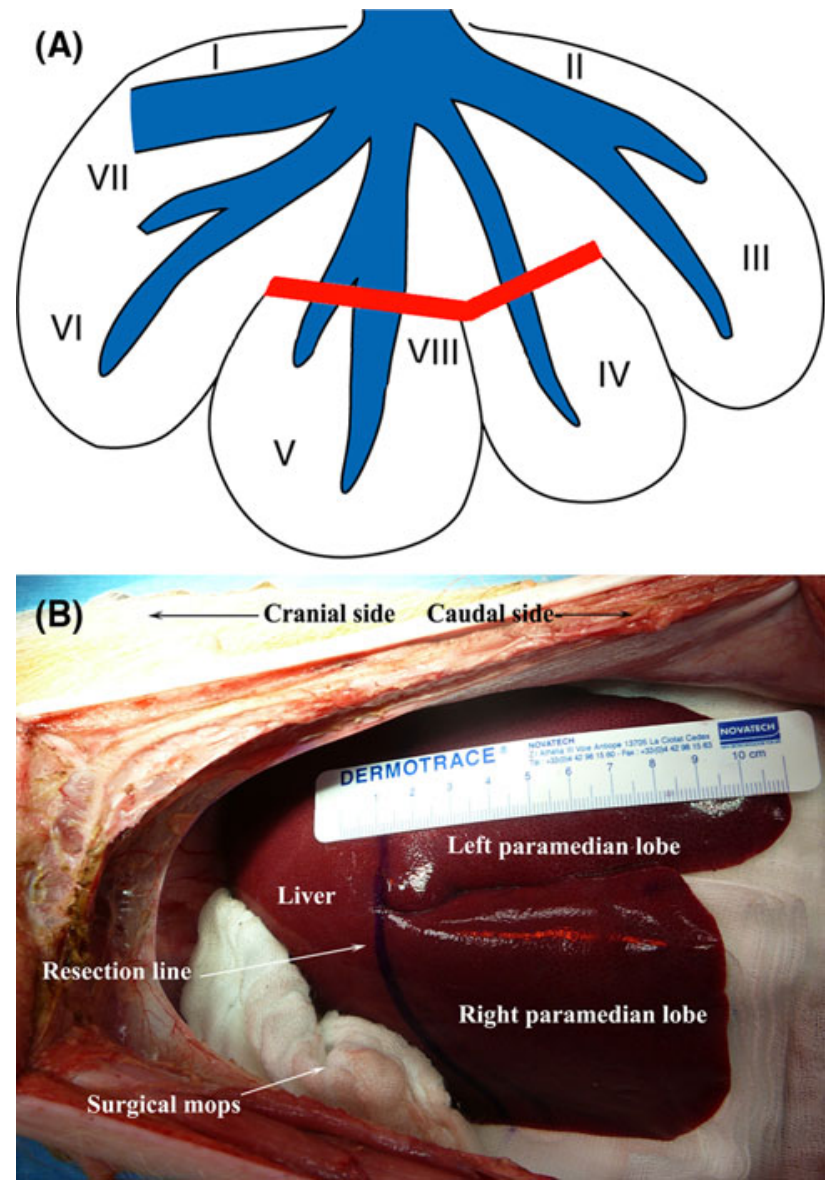

FIG. 2 a Two liver resections were performed on each pig (the red lines on the diagram indicate the planned resection lines). b Representative pig liver. The right and left paramedian lobes and the resection line are indicated
(Fig. 3). HIFU application began along the marked line on the glissonian surface using the toroid transducer under manual control; this created a single defined ischemic necrotic lesion in the liver parenchyma. The $7.5-\mathrm{MHz}$ ultrasound imaging probe placed in the center of the HIFU device allowed real-time guidance during the treatment. After the first single HIFU lesion was performed, if necessary, the focus of the probe was changed to obtain a full thickness precoagulation of the resection plane and then the toroid transducer was moved along the planned resection line, and another HIFU lesion was induced next to the first lesion. The positioning of the HIFU-induced lesions resulted in a homogeneous "wall-shaped" lesion that encompassed the plane of resection.

Resection was performed in the middle of the precoagulated zone. The liver resection technique was the same for all 3 groups and was performed using a Kelly clamp claw, a suction device, and metallic clips (SLS-CLIP B2180-A, Vitalitec International). In group B, resection was done under intermittent clamping of the hepatic stalk
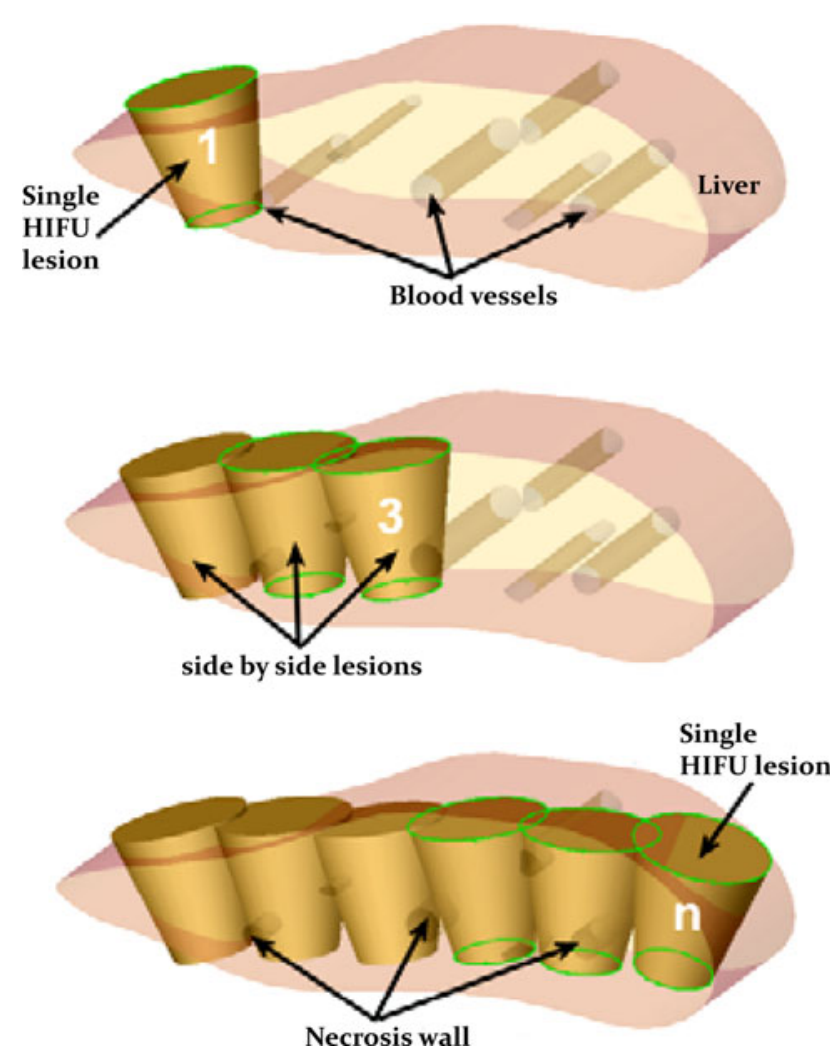

FIG. 3 "Precoagulation line" is created using ultrasound guidance by positioning multiple HIFU lesions side by side. After the first single HIFU lesion is performed, if necessary, the focus of the probe is changed to obtain a full thickness precoagulation of the resection plane, and then the toroid transducer is moved along the planned resection line, and another HIFU lesion is induced next to the first lesion 
using intermittent hepatic inflow occlusion (duration, $10 \mathrm{~min}$ ) followed by a short period of reperfusion (duration, $5 \mathrm{~min}$ ). In group $\mathrm{C}$, hepatic resection was obtained without any vascular clamping.

Additional surface hemostasis on the hepatic tissue was performed at the end of resection using a monopolar dissector. All blood loss and biliary leakage were controlled by clips and surgical sutures as necessary. At the end of the surgical procedure, the laparotomy was closed in all animals with a running suture (2 planes). A video camera (DCRPC110E PAL, Sony) recorded all phases of each resection.

\section{Postresection Analysis}

Immediately after each hepatic resection, the removed specimens including a grid were photographed, and these images were thereafter digitally processed. The entire abdominal cavity was inspected for collateral HIFU effects on adjacent organs, that is, burns. All the animals were examined clinically twice a day by a veterinary surgeon until postoperative day D15.

Postoperative analgesia was administered by a fentanyl patch. Plasma samples were withdrawn from a central venous catheter on postoperative days D1, D4, D7, and D15 for the following determinations: hemoglobin level, hematocrit, thrombocyte count, AST, ALT, PT, APTT, bilirubin, and ammonia (Fig. 4). The results were compared with normal values in accordance with the Canadian Council on Animal Care. ${ }^{23}$

On D4 and D7, an echograph was used to assess liver size, the presence of perihepatic fluid collections, and the permeability of the main hepatic and portal vessels and to inspect the biliary tract.

Animals were euthanized on D15. The abdominal cavity and internal organs were inspected carefully, and livers were weighed, measured, and analyzed by a pathologist. Histopathological analysis was performed on liver tissue to verify coagulation necrosis, hemostasis, and biliostasis.

\section{Assessment Criteria}

The primary criterion was to assess whether HIFUassisted liver resection resulted in reduced blood loss compared with liver resection with or without clamping. Blood loss referred to hepatic resection was systematically determined by weighing all blood-soaked surgical mops on a high-precision scientific scale (PB1502, Mettler Toledo). The aspirated fluid (blood suctioned out of the abdomen) was weighed as well. The secondary assessment criteria were blood loss $/ \mathrm{cm}^{2}$ of resection area, clip density, duration of the resection procedure, and morbidity and mortality in each group.

\section{Statistical Analysis}

Animals were divided into 3 groups to evaluate HIFUassisted liver resection (group A) vs liver resection with or without clamping (groups B and C, respectively). Using a Wilcoxon rank-sum test with a .05 2-sided significance level for each 2-by-2 comparison (group A vs group B and group A vs group C), 14 resections were required in each group to detect a difference in mean blood loss of $100 \mathrm{~mL}$ with $80 \%$ power, assuming a common standard deviation of $81.2 \mathrm{~mL}$ based on preliminary data.

Quantitative variables were compared between groups (group A vs group B and group A vs group C) using a Wilcoxon rank-sum test with a .05 2-sided significance level.

\section{RESULTS}

All surgeries were performed by a single researcher on 21 12-14-week-old Landrace pigs. There were 14 separate liver resections performed in each group ( 2 per animal). Total hepatectomy took place on D1 after surgery $(n=1$; 1 pig in group $\mathrm{C}$ died of a massive left pulmonary thrombotic embolism) and on D15 ( $n=20$ pigs).

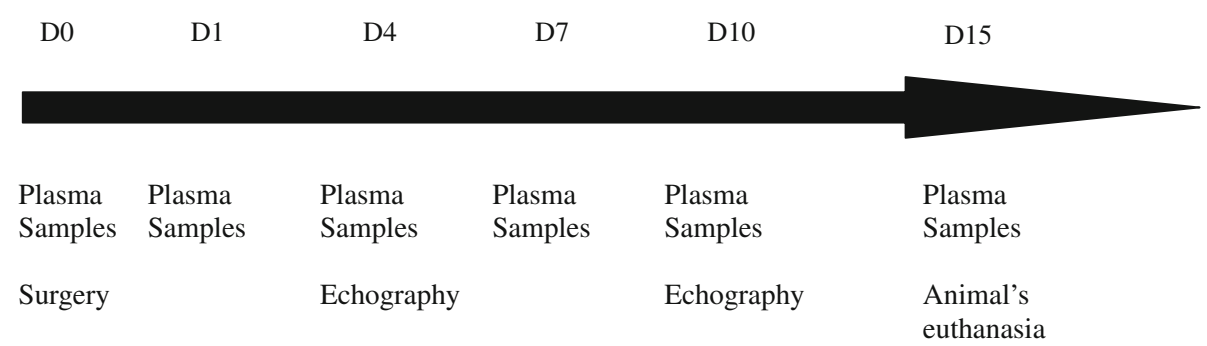

FIG. 4 Study overview. High-intensity focused ultrasound (HIFU)assisted hepatic resection was performed on pigs on day 0 (D0) using a handheld probe, and the animals were monitored until euthanasia on day 15 (D15). Plasma samples were withdrawn from each animal from a central venous catheter for the following laboratory

determinations: hemoglobin level, hematocrit, thrombocyte count, aspartate aminotransferase (AST), alanine aminotransferase (ALT), prothrombin time (PT), activated partial thromboplastin time (APTT), bilirubin, and ammonia 
The median weight of the harvested livers was $881.3 \mathrm{~g}$ [666.2-1263.9], the median resected rate was $11.38 \%$ [6.1$16.4]$, and the total mass of resected liver was $100 \pm 25 \mathrm{~g}$ [57.6-153.5]. The median resection line length was $80 \mathrm{~mm}$ [60-117], and the median depth of the resected lobe was $24 \mathrm{~mm}$ [16-32]. The median resected surface area was $15.52 \mathrm{~cm}^{2}$ [8.7-49.7]. All the values in the 3 groups were homogeneous (Table 1A), but depth of the resection lobe (greater in group A than group B and C) and resection rate that was slightly greater in group $\mathrm{C}$ than in group $\mathrm{A}$. Finally, this does not affect blood loss referred to hepatic resection area when we compare the results in group $\mathrm{A}$ and $\mathrm{C}$.

In Group A, HIFU treatment was visible on both sides of the transection line (Fig. 4). The median number of HIFU lesions needed to obtain coagulative necrosis of the resection line was 8.9 lesions. $^{5-12}$ All vessels $<5 \mathrm{~mm}$ in diameter were sealed successfully using HIFU precoagulation. Surgical clips were used to control vessels $>5 \mathrm{~mm}$ in diameter. In group A, no additional surface hemostasis was needed. In groups B and C, a monopolar dissector was used to achieve complete liver hemostasis.

\section{Histological Analysis}

Histological analyses were performed on the resected specimens on D0 (the day of surgery) and on D15. After specimen fixation and sectioning, homogeneous lesions were identified on the resection line in samples from pigs in group A. Lesions consisted of a central yellow/white area

TABLE 1 A Animal and resection characteristics and B animal and plasma sample analysis

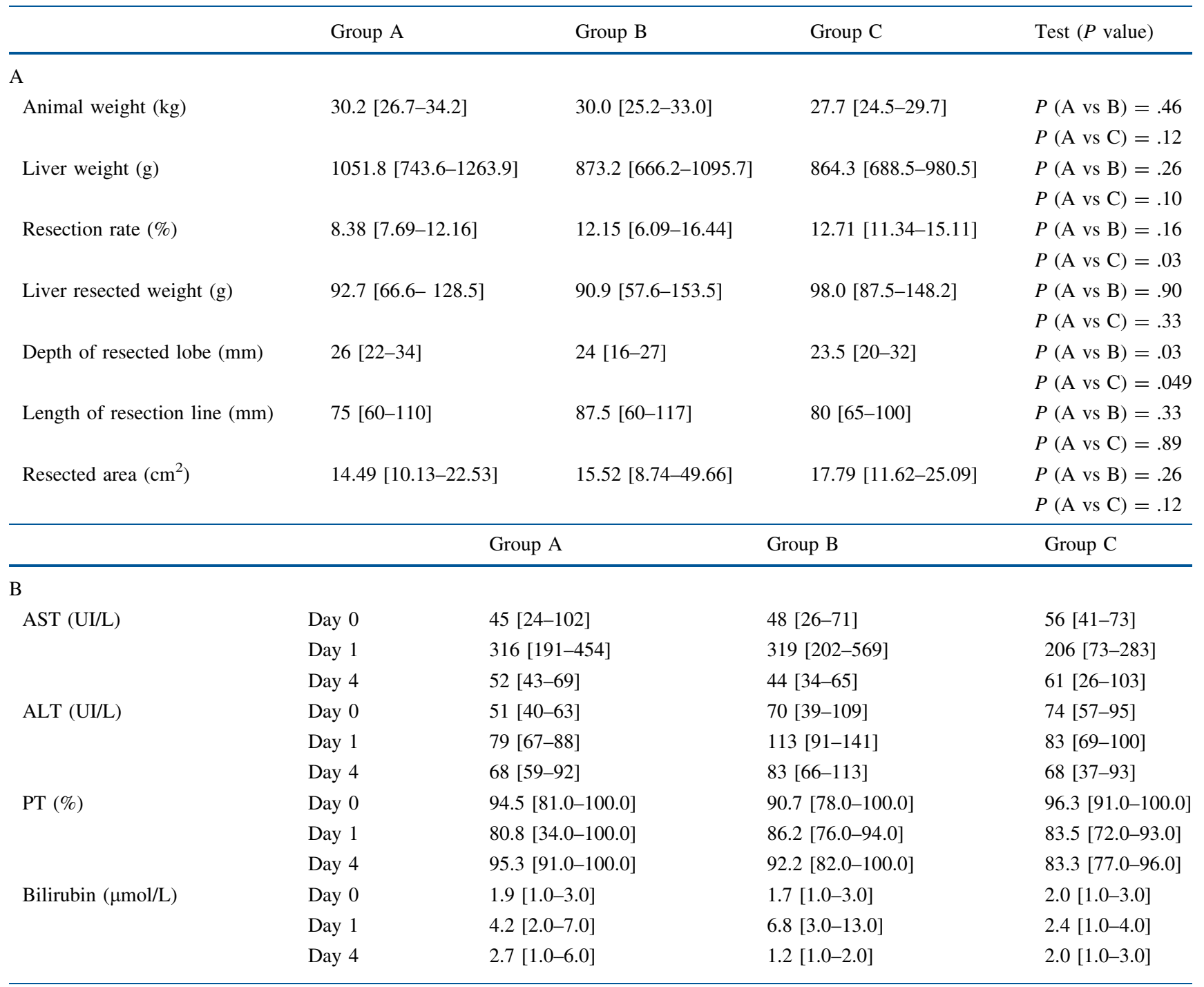

Animals are divided into 3 groups to evaluate HIFU-assisted liver resection (group A) vs liver resection with or without clamping (groups B and $\mathrm{C}$, respectively)

All values are expressed as median [range] 
surrounded by an outer dark red zone. Histological analysis revealed coagulated necrotic tissue, no incomplete destruction was found. A transition zone was present between the coagulated zone (pyknotic nuclei, cytoplasm containing few vacuoles) and normal liver parenchyma (Fig. 5).

In all animals, HPS staining showed a homogeneous hepatic resection line with intense reactive fibroses. Clips were integrated into the scar tissue that was present on the resection line.

\section{Blood Loss, Clip Density, and Treatment Time}

The median blood loss in group A was $68 \mathrm{~mL}$ (28489.2), which was significantly lower than in group B $(194.7 \mathrm{~mL} ; 58.5-383.8) \quad(P=.02)$ and in group $\mathrm{C}$ (200.05 mL; 106.5-523) $(P=.007)$. Median blood loss/ $\mathrm{cm}^{2}$ resection area was $4.77 \mathrm{~mL} / \mathrm{cm}^{2}(1.66-21.71)$ in group A, $11.35 \mathrm{~mL} / \mathrm{cm}^{2}(3.67-17.94)$ in group $\mathrm{B}$, and $12.22 \mathrm{~mL} / \mathrm{cm}^{2}$ (7.81-29.97) in group C.

The median clip density during liver transection was $0.78 \mathrm{clip} / \mathrm{cm}^{2}(0.35-1.37)$ in group A, $1.61 \mathrm{clip} / \mathrm{cm}^{2}(0.83-$ $2.45)$ in group $B$, and $1.57 \mathrm{clip} / \mathrm{cm}^{2}(0.80-3.16)$ in group $\mathrm{C}$.

The median surgical resection duration was $12 \mathrm{~min}(7-$ 30) in group A, 21 min (15-39) in group B, and 19 min (10-27) in group C.
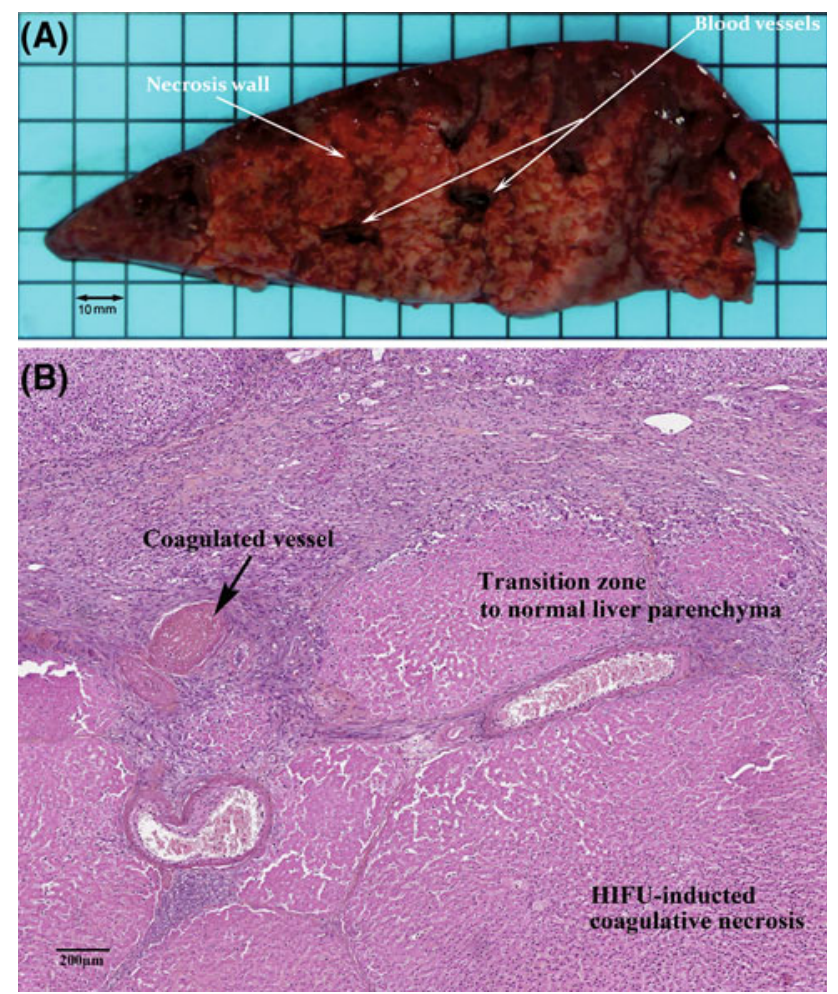

FIG. 5 Resection line on postoperative day 15 in a representative pig in group A. a Macroscopic view. b Microscopic view

\section{Morbidity and Mortality}

Morbidity and mortality reflect tolerance of the treatment. In this study, all but 1 pig survived ( 1 group $\mathrm{C}$ pig died of a massive left pulmonary thrombotic embolism), and all pigs had a normal postoperative recovery until euthanasia on D15. Clinical examinations were performed daily, and results of the plasma sample analysis were normal from D4 onwards (Table 1B). Extracorporeal echographic liver examinations, performed on D4 and D10, allowed visualization of the remaining parenchyma. We had only a single case of subglissonian fluid collection $(63 \mathrm{~mL})$ in an animal in group $\mathrm{B}$; it did not require drainage.

After euthanasia, 1 liver in each group (i.e., a total of 3 livers) was found to have a small uncomplicated fluid collection. The 18 remaining animals $(86 \%)$ did not show any complications. Most of the clips were still on the resection line, and we observed adhesions along the resection line and on contiguous organs.

\section{DISCUSSION}

HIFU liver precoagulation is a promising technique for minimizing blood loss during hepatic resection without the Pringle maneuver. Avoiding dissection and pedicle clamping can prevent liver ischemia-reperfusion injury, which is known to predispose patients to postoperative liver failure. This study demonstrated the feasibility, safety, and reproducibility of HIFU-assisted hepatic resection during an open procedure in an animal model.

HIFU coagulative necrosis can target a precise focal volume within the liver without any puncture or impairment of overlying structures, such as major blood vessels; even structures within the path of the ultrasonic beam are unharmed. ${ }^{18}$ This represents a major advantage compared with techniques that use heat coagulation because coagulative necrosis is induced without risk of needle-track seeding. ${ }^{24,25}$

The toroid HIFU transducer used in this study enabled access to extended homogeneous complex lesions without the encumbrance of a device coupled to a reflector, as described previously. ${ }^{26}$ Juxtaposition of the HIFU-induced elementary lesions created a "wall" of necrosis that facilitated resection in hepatic parenchyma, resulting in reduction of intraoperative blood loss compared with standard hepatic resection techniques. Vessels less than $5 \mathrm{~mm}$ in diameter located along the resection plane are sealed by HIFU coagulative necrosis, while larger vessels need to be isolated, clipped, and cut using surgical scissors. Hemostasis is therefore easily achieved with fewer surgical clips. In contrast to other techniques used to assist liver resection, in this study HIFU biliostasis was definitive 
without any postoperative bile leaks. ${ }^{14}$ Morbidity related to treatment was acceptable: no animal died as a result of HIFU-assisted hepatic resection.

Regarding HIFU precoagulation duration, the toroid geometry of the probe was optimized to induce a large coagulation volume (volume: $7.0 \pm 2.5 \mathrm{~cm}^{3}$ ) in only $40 \mathrm{s.}^{27}$

The results of this study indicated that this procedure could be used in human patients for whom precoagulation may offer better control of blood loss, for example, for patients with postchemotherapy fragile liver. ${ }^{28}$ Patients undergoing iterative hepatic resection might also benefit from HIFU precoagulation: In these cases, segmental and nonanatomical resections to spare liver parenchyma can be mandatory. Usually segmental and nonanatomical resections are classified as minor hepatectomies, but they can be technically demanding and result in more bleeding than for major resections. In this same situation, intermittent hepatic clamping, which is often used to prevent bleeding during hepatic resection, and liver mobilization can be difficult because of previous procedures and postoperative adhesions. In such situations, HIFU may be useful since precoagulation necrosis can help to achieve a bloodless resection without using intermittent hepatic inflow occlusion.

In this study, the resection was performed in the middle of a coagulated zone, and the narrow coagulated zone in the resection margin may improve the clearance of this margin and thus reduce the incidence of local recurrence. ${ }^{29}$ This represents a major advantage when a sterilized margin cannot be anatomically improved, for example, because of hepatic veins, hepatic pedicle, and so on. In such cases, resection in conjunction with ultrasound precoagulation may be an option for a surgical strategy that maintains oncological radicality.

Finally, this technique permits excellent control of the surgical resection line and is easy to reproduce. Fine control is possible because each lesion induced by HIFU is visible with contrast on sonograms performed by the imaging probe that is integrated within the HIFU toroid transducer. This allows 4-dimensional control (topographic and real-time visualization) of the resection line during the procedure.

What we call "focused ultrasound liver surgery" thus represents progress in the use of ultrasound in liver surgery: ultrasound can first be used to identify lesions and then aid in liver tumor resection or destruction. ${ }^{18} \mathrm{HIFU}$ broadens the concept of ultrasound-assisted liver surgery and helps optimize the surgical strategy. We demonstrated previously that the same HIFU probe that is used to assist hepatic resection can also be used to destroy hepatic lesions. ${ }^{30}$ A combined approach, that is, lesion resection plus focal destruction of lesions that cannot be excised, is a potentially curative treatment option for patients with multiple bilobar hepatic metastases. This strategy may expand the number of patients who can successfully undergo surgery and achieve positive oncological outcomes.

We have already begun the first HIFU applications in human patients in open liver surgery.

In conclusion, HIFU-assisted hepatic resection is a safe technique that greatly reduces bleeding during resection and also allows real-time ultrasound guidance.

ACKNOWLEDGMENT The authors thanks dr Claire Cropet (Unité de Biostatistique et d'Evaluation des Thérapeutiques Centre Léon Bérard) for statistical revision of the data in the present manuscript. This work was partly supported by funding from the Cancéropôle Lyon Auvergne Rhône Alpes (Grant No. PDC 2006.4.8).

OPEN ACCESS This article is distributed under the terms of the Creative Commons Attribution Noncommercial License which permits any noncommercial use, distribution, and reproduction in any medium, provided the original author(s) and source are credited.

\section{REFERENCES}

1. Kooby DA, Stockman J, Ben-Porat L, Gonen M, Jarnagin WR, Dematteo RP, et al. Influence of transfusion on perioperative and long-term outcome in patients following hepatic resection for colorectal metastases. Ann Surg. 2003;237:860-70.

2. Sitzmann JV, Greene PS. Perioperative predictors of morbidity following hepatic resection for neoplasm: a multivariate analysis of a single surgeon experience with 105 patients. Ann Surg. 1994;219:13-7.

3. Gozzetti G, Mazziotti A, Grazi GL, Jovine E, Gallucci A, Gruttadauria S, et al. Liver resection without blood transfusion. Br J Surg. 1995;82:1105-10.

4. Rosen C B, Nagorney D M, Taswell H F, Helgeson SL, Ilstrup DM, van Heerden JA, et al. Preoperative blood transfusion and determinants of survival after liver resection for metastatic colorectal carcinoma. Ann Surg. 1992;216:493-505.

5. Man K., Lo C.-M., Liu C.-L., Zhang ZW, Lee TK, Ng IO, et al. Effects of the intermittent Pringle maneuver on hepatic gene expression and ultrastructure in a randomized clinical study. $\mathrm{Br} J$ Surg. 2003;90:183-9.

6. Belghiti J, Noun R, Malafosse R, Jagot P, Sauvanet A, Pierangeli $\mathrm{F}$, et al. Continuous versus intermittent portal triad clamping for liver resection: a controlled study. Ann Surg. 1999;229:369-75.

7. Torzilli G, Makuuchi M, Midorikawa Y, Sano K, Inoue K, Takayama $\mathrm{T}$, et al. Liver resection without total vascular exclusion: hazardous or beneficial? An analysis of our experience. Ann Surg. 2001;233:167-75.

8. Petrowsky H, McCormack L, Trujillo M, Selzner M, Jochum W, Clavien PA. A prospective, randomized, controlled trial comparing intermittent portal triad clamping versus ischemic preconditioning with continuous clamping for major liver resection. Ann Surg. 2006;244:921-8; discussion 928-30.

9. Helling TS, Wogahn BM, Olson SA, Evans LS, Reddy BR, VanWay C 3rd. The effect of prostaglandin E1 on liver adenine nucleotides and cytoplasmic enzymes in a porcine model of normothermic hepatic ischemia. Hepatology. 1995;22:1554-9.

10. van Wagensveld BA, van Gulik TM, Gelderblom HC, Scheepers JJ, Bosma A, Endert E, et al. Prolonged continuous or 
intermittent vascular inflow occlusion during hemihepatectomy in pigs. Ann Surg. 1999;229:376-84.

11. Rau HG, Buttler ER, Baretton G, Schardey HM, Schildberg FW. Jet-cutting supported by high frequency current: new technique for hepatic surgery. World J Surg. 1997;21:254-9; discussion 259-60.

12. Weber JC, Navarra G, Liao LR, Nicholls JP, Jensen SL, Habib NA. New technique for liver resection using heat coagulative necrosis. Ann Surg. 2002;236:560-3.

13. Poon RT, Fan ST, Wong J. Liver resection using a saline linked radiofrequency dissecting sealer for transection of the liver; $J \mathrm{Am}$ Coll Surg. 2005;200:308-13.

14. Kim J, Ahmad SA, Lowy AM, Buell JF, Pennington LJ, Soldano DA, et al. Increased biliary fistulas after liver resection with the harmonic scalpel. Am Surg. 2003;69:815-9.

15. Satoi S, Kamiyama Y, Matsui Y, Kitade H, Kaibori M, Yamamoto $\mathrm{H}$, et al. Clinical outcome of 214 liver resections using microwave tissue coagulation. Hepatogastroenterology. 2005;52:1180-5.

16. Illing RO, Kennedy JE, Wu F, ter Haar GR, Protheroe AS, Friend PJ, et al. The safety and feasibility of extracorporeal highintensity focused ultrasound (HIFU) for the treatment of liver and kidney tumours in a Western population. Br J Cancer. 2005;93: $890-5$.

17. Kennedy JE, Wu F, ter Haar GR, Gleeson FV, Phillips RR, Middleton MR, et al. High-intensity focused ultrasound for the treatment of liver tumours. Ultrasonics. 2004;42:931-5.

18. Parmentier H, Melodelima D, N'Djin A, Chesnais S, Chapelon JY, Rivoire M. High-intensity focused ultrasound ablation for the treatment of colorectal liver metastases during an open procedure: study on the pig. Ann Surg. 2009;249:129-36.

19. Melodelima D, N'Djin WA, Parmentier H, Chesnais S, Rivoire M, Chapelon JY. Thermal ablation by high-intensity-focused ultrasound using a toroid transducer increases the coagulated volume. Results of Animal Experiments. Ultrasound Med Biol. 2009;35:425-35.

20. Melodelima D, N'Djin WA, Favre-Cabrera J, Parmentier H, Rivoire M, Chapelon JY. Thermal ablation produced using a surgical toroidal High Intensity Focused Ultrasound device is independent from hepatic inflow occlusion, Phys Med Biol. 2009;54:6353-68.

21. Melodelima D, Cathignol D. Cancer treatment by ultrasound: increasing the depth of necrosis. Appl Phys Lett. 2004;84:5365-7.

22. Melodelima D, Salomir R, Mougenot C, Moonen C, Cathignol D. 64-element intraluminal ultrasound cylindrical phased array for transesophageal thermal ablation under fast MR temperature mapping: an ex vivo study. Med Phys. 2006;33:2926-34.

23. Olfert ED, Cross BM, Mc William AA. Manuel sur le soin et l'utilisation des animaux d'expérimentation. Ottawa: Canadian Council on Animal Care; 1993.

24. Llovet JM, Vilana R, Brú C, Bianchi L, Bianchi L, Salmeron JM, Boix L, et al. Increased risk of tumor seeding after percutaneous radiofrequency ablation for single hepatocellular carcinoma. Hepatology. 2001;33:1124-9.

25. de Baère T, Risse O, Kuoch V, Dromain C, Sengel C, Smayra T, et al. Adverse events during radiofrequency treatment of 582 hepatic tumors. AJR Am J Roentgenol. 2003;181:695-700.

26. Zderic V, O'Keefe GE, Foley JL, Vaezy S. Resection of abdominal solid organs using high-intensity focused ultrasound. Ultrasound Med Biol. 2007;33:1251-8.

27. Melodelima D, N'Djin A, Parmentier H, Chesnais S, Rivoire M, Chapelon J-Y. Ultrasound surgery with a toroic transducer allows the treatment of large volumes over short periods of time. Appl Phys Lett. 2007;91:193901.

28. Rubbia-Brandt L, Audard V, Sartoretti P, Roth AD, Brezault C, Le Charpentier $M$, et al. Severe hepatic sinusoidal obstruction associated with oxaliplatin-based chemotherapy in patients with metastatic colorectal cancer. Ann Oncol. 2004;15:460-6.

29. Kokudo N, Miki Y, Sugai S, Yanagisawa A, Kato Y, Sakamoto $\mathrm{Y}$, et al. Genetic and histological assessment of surgical margins in resected liver metastases from colorectal carcinoma: minimum surgical margins for successful resection. Arch Surg. 2002;137: $833-40$

30. N'Djin WA, Melodelima D, Parmentier H, Chesnais S, Rivoire M, Chapelon JY. Utility of a tumor-mimic model for the evaluation of the accuracy of HIFU treatments. results of in vitro experiments in the liver. Ultrasound Med Biol. 2008;34:1934-43. 